\title{
Congenital Epulis: About Four Cases in Newborns
}

\author{
Aiat Allah Skiredj ${ }^{1 *}$, Nawfal Fejjal ${ }^{2}$
}

\author{
${ }^{1}$ Plastic and Reconstructive Surgery Department of University Children's Hospital of Rabat, Ibn Sina UHC, Rabat, Morocco \\ ${ }^{2}$ Professor, Plastic and Reconstructive Surgery Department of University Children's Hospital of Rabat, Ibn Sina UHC, Rabat, Morocco
}

DOI: $10.36347 /$ sjmcr.2021.v09i03.026

| Received: 06.03.2021 | Accepted: 24.03.2021 | Published: 25.03.2021

*Corresponding author: Aiat Allah Skiredj

Congenital epulis or Congenital granular cell epulis (CGCE) is a rare benign tumour in the neonate. It arises from the gingival mucosa. The most affected oral site is located around the canine/incisor region of the maxillary alveolar ridge This benign condition can be life threatening when it is obstructive. It has predominance for females. CGCE's histogenesis remains obscure and controversial. We report 4 cases of newborns females and one male with features of obstructive congenital epulis arising from both maxillary and mandibular alveolar ridge, interfering with breastfeeding. Diagnosis was suspected clinically and confirmed by histology and immunohistochemical. Outcome was good after prompt surgery for the 3 cases. 2 of patient showed satisfactory postoperative healing and excellent health at both the 10-day recall appointment follow-up but one of them was lost to follow up.

Keywords: Epulis, newborn, tumor, congenital.

Copyright $(\mathcal{C} 2021$ The Author(s): This is an open-access article distributed under the terms of the Creative Commons Attribution 4.0 International License (CC BY-NC 4.0) which permits unrestricted use, distribution, and reproduction in any medium for non-commercial use provided the original author and source are credited.

\section{INTRODUCTION}

Congenital granular cell epulis (CGCE) or congenital gingival cell tumour is a rare congenital tumor found in newborns. Less than 250 cases are reported to date. First time described by the pathologist Dr. Neumann in 1871 who presented it as a « congenital epulis » [1]. It is a benign tumor which arises from the gingival mucosa. Epulis is a word derived from the ancient Greek language and translates into «swelling on the gingiva ». It has predominance for females with an 8:1 ratio in relation to males and is exclusively encountered in the oral cavity.

The most affected oral site is located around the canine/incisor region of the maxillary alveolar ridge, where the lesion arises as a solitary pedunculated mass. CGCE's histogenesis remains obscure and controversial [2]. The vital prognosis can be at stake in the case of an obstructive tumor. Surgical treatment should be prompt in the presence of obstructive symptoms that interfere with breathing or eating, or in the event of haemorrhage.

We present 4 cases of newborns 3 females and 1 male which diagnosis was suspected clinically and confirmed by histology.

\section{CASe Reports}

Case 1

The first case was a 7-day-old female born at time, who not experience any difficulty regarding breathing or deglutition. The tumor was located into the maxillar oral ridge, multilobee measuring $3 \mathrm{~cm}$ of long axis, pink color with a smooth and painless surface with no prominent blood vessels. The tumor interfered with feeding, and closing the mouth (Figure-1). Complete surgical excision was the treatment of choice in this case, and the procedure was performed under both general anesthesia. The post-operative course was uncomplicated. The patient presents an excellent health at the 2 years recall appointment with any aesthetic anomaly with good closure of the mouth (Figure-2). The diagnosis of CGCE was confirmed histology.

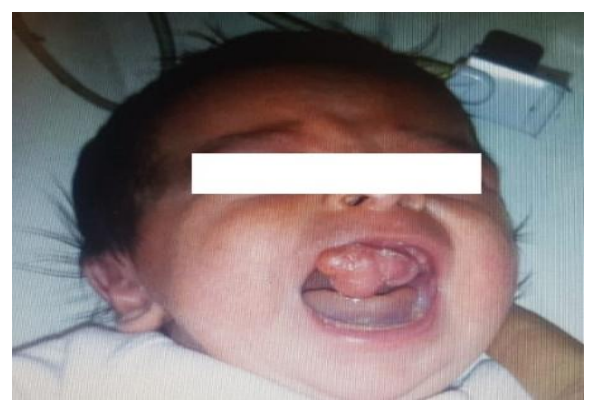

Fig-1: Congenital epulis from the maxillar gengiva 
Aiat Allah Skiredj \& Nawfal Fejjal., Sch J Med Case Rep, Mar, 2021; 9(3): 288-291

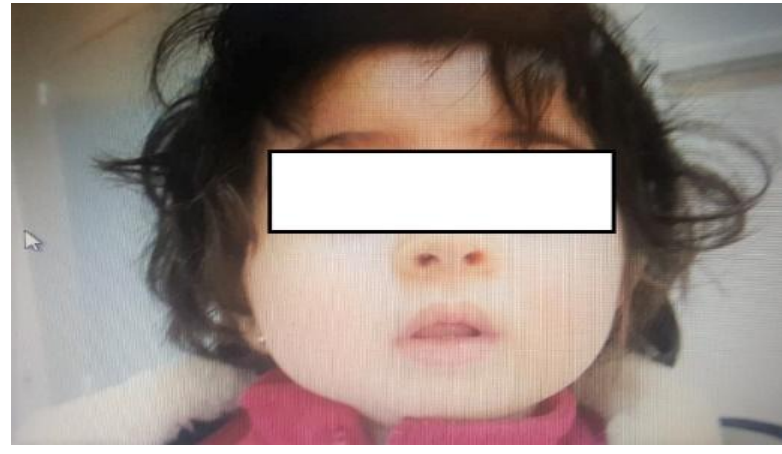

Fig-2: 2 years after surgery

\section{Case 2}

It about a 10 days old male born at time by an uncomplicated pregnancy. One pedunculed mass bilobeted measuring $2 \mathrm{~cm}$ located in the mandibular alveolar ridge was detected clinically at birth without any difficulty regarding breathing (Figure-3). The tumor was removed under general anaesthesia (Figure4). There wasn't any complication in the post-operative course. The patient showed satisfactory postoperative healing. No recurrence has been noticed on postoperative visits and perfect reconstitution of the maxillary alveolar ridge has occurred without no obstacle to dentition.

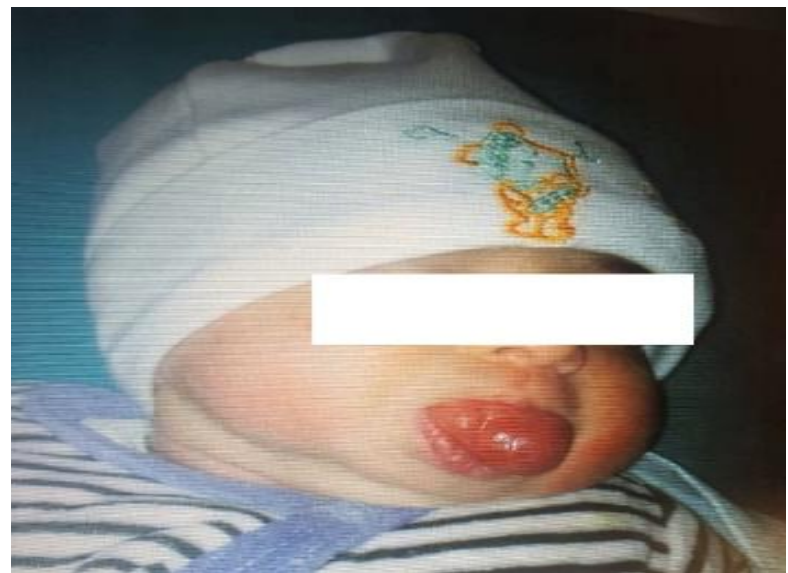

Fig-3: 10 days old boy with a pedunculed mass

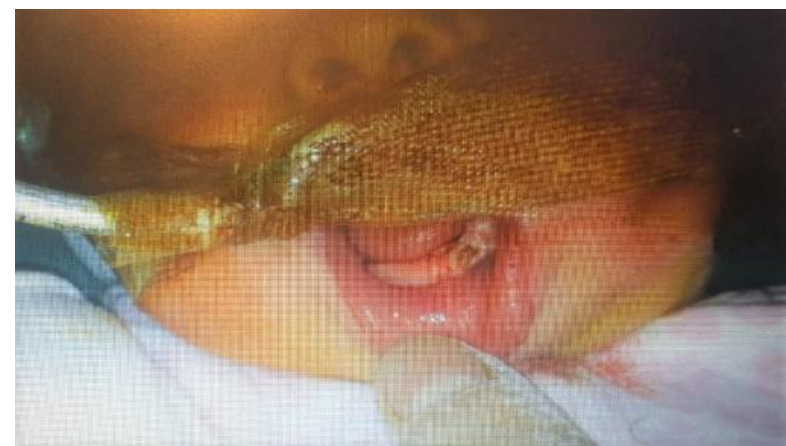

Fig-4: Result after excision

Case 3

The third case, a 5 days old female born at time by caesarean. The suspicion of congenital epulis was done in delivery room. The tumor was located in the left side of mandibular alveolar without any interference with breathing or feeding (Figure-5). Complete surgical excision was the treatment of choice, and the procedure was performed under both general anaesthesia without any complication. The patient was lost to follow up but the histology confirms the diagnosis of CGGE.

Microscopic examination demonstrated a tumor measuring $7 \mathrm{~mm}$ composed of round or ovoid cells with abundant granular eosinophilic cytoplasm and small eccentric displaced nuclei. The tumorcells were separated by a fine vascular network.

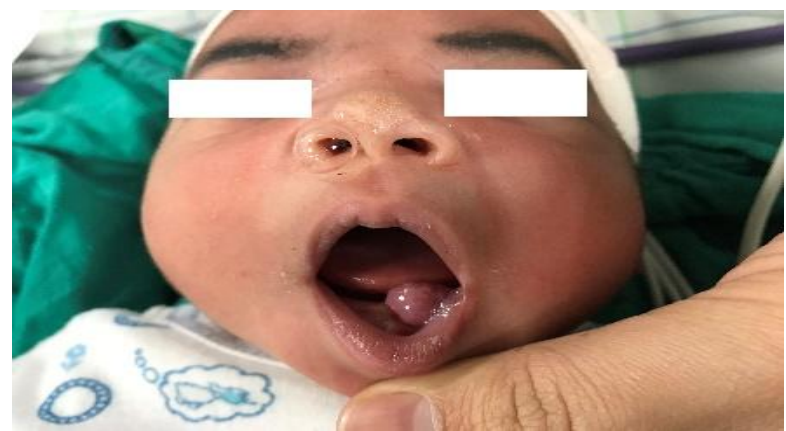

Fig-5: 5 days old female with a congenital epulis

\section{Case 4}

The last case is a recent case about a 7 days old female born at time without any complication. The diagnosis of congenital epulis was made at birth. The tumor was located in the maxillar oral ridge, with 2,5 $\mathrm{cm}$ of long axis, interfering with feeding (Figure-6). The complete surgical excision was done under general anaesthesia without any complication (Figure-7). The histology confirms the diagnosis of CGGE.

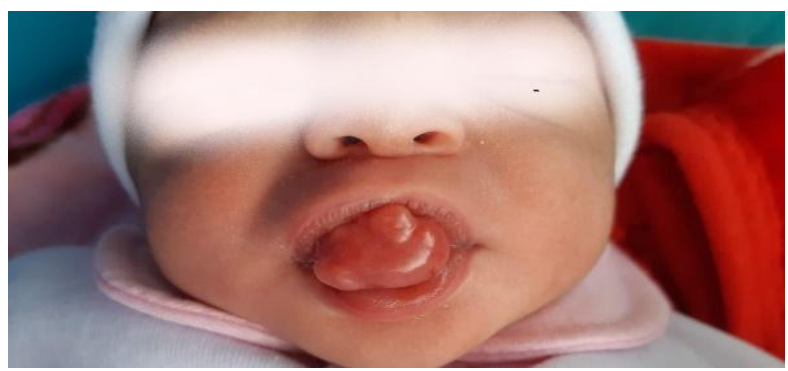

Fig-6: 7 days old female with a congenital epulis measuring $2,5 \mathrm{~cm}$

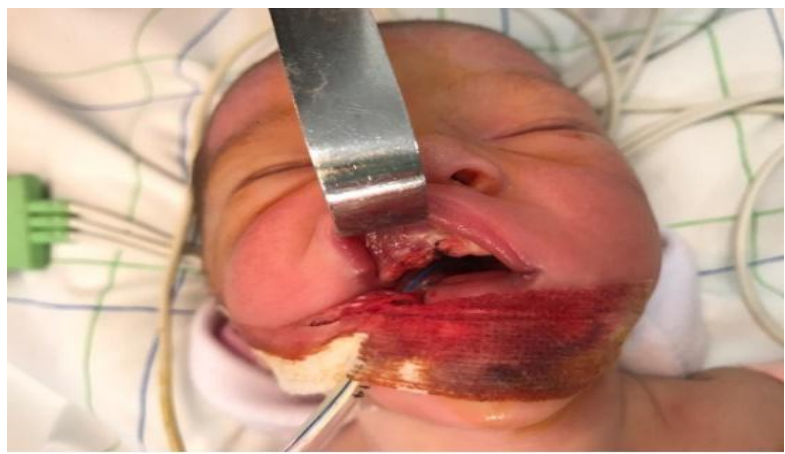

Fig-7: The final result after excision 


\section{DISCUSSION}

This benign lesion, CGCE, predominantly affects female infants with an 8:1 ratio in relation to male infants and is encountered 3 times more often on the maxilla than on the mandible [6].

Clinically, majority of cases appears around the canine/incisor region of the maxillary alveolar ridge as a solitary pedunculated. The exact pathogenesis of this benign tumor is still unclear and several theories have been put forward: myoblastic, neurogenic, odontogenic, fibroblastic or endocrine [8]. A study in rats found a correlation between tumor appearance and oestrogen exposure in utero. [9] Owing to this fact and the correlation to female newborn predominance, it is believed that maternal hormones stimulate tumor growth. Paradoxically, no oestrogen or progesterone receptors have been detected in CGCE cells [10]. Nevertheless, multiple lesions or multiple localizations have been described in 5 to $16 \%$ of cases [11]. The tumor is most often unique, firm, of fairly regular surface, sometimes polylobate, sessile or pedicle, pink or red in color, not painful on palpation [8-12].

The size of the tumor varies from a few millimetres to ten centimetres in its largest diameter. The classic clinical appearance of the mass often allows the diagnosis to be suspected. In the foetus, large lesions can hinder swallowing with the formation of a hydramnios, sometimes acute, which leads to the diagnosis of the tumor $[1,4,11]$. The risk of bleeding from these large lesions (for example tearing of the pedicle) can justify delivery by caesarean [1].It is also imperative for clinicians to be aware of the differential diagnoses surrounding CGCE including fibroma, hemangioma, lymphangioma, Schwannoma, heterotopic gastrointestinal cyst, and rhabdomyoma $[6,14]$. CGCE is firmer than the hemangioma with a lighter colored mucosa than the latter. Granular cell myoblastoma most often arises from the dorsal or ventral aspect of the tongue and is exceptionally present at birth $\neg[1,11]$. The teratoma of the oral cavity is called an epignathic teratoma when it is very large; although exceptional, this lesion presents a serious nature when it is obstructive [1]. Imaging (ultrasound-doppler or MRI) can guide the diagnosis by showing hypervascularization in the case of hemangioma or the presence of other tissues in the case of teratoma. Excision within the nearest postnatal period is the treatment of choice regarding CGCE [4, 12, 14]. Recurrence rarely occurs, and the prognosis is excellent $[3,14]$. The CGCE not involve or damage the patients' dentition. Reported dentition damage seems to be an iatrogenic damage related to the surgical treatment $[12$, 14].

Histology confirms diagnosis by showing tumor formed of large round or polygona cells centered by round or oval nuclei, with a granular cytoplasm and a tumor stroma. The CGCE distinguishes itself from the others giant cell tumors by its location exclusively gingival, the presence of an epithelium typical of the mucosa, the vascular supply of the very rich tumor stroma in collagen and the absence of nervous components $[1,7,9,12]$. Although histologically close to cell tumors grainy in adults, this tumor is differentiated by a different antigenic expression: congested tumors nitals do not express the S100 protein and the neuronspecific enolase (NSE) unlike those in adults [1].

\section{CONCLUSION}

Congenital epulis or Congenital granular cell epulis (CGCE) is a rare benign tumour in the neonate. It arises from the gingival mucosa. This benign condition can be life threatening when it is obstructive. It has predominance for females. Diagnosis was suspected clinically and confirmed by histology and immunohistochemical. The treatment is a complete surgical excision. Histology confirms diagnosis by showing tumor formed of large round or polygonal cells centered by round or oval nuclei, with a granular cytoplasm and a tumor stroma.

Conflict of interest: No financial interests to declare in relation to the content of this article and have received no external support related to this article.

\section{REFERENCES}

1. Guven S, Kaymakci A, Bugday MS, Yilmaz M. Congenital granular cell tumor. J Craniofac Surg. 2009;20(3):976e7.

2. Bang KO, Bodhade AS, Dive AM. Congenital granular cell epulis of a newborn. Dent Res J (Isfahan). 2012;9(Suppl 1):S136e8.

3. Loyola AM, Gatti AF, Pinto Jr DS, Mesquita RA. Alveolar and extra-alveolar granular cell lesions of the newborn: report of case and review of literature. Oral Surgery, Oral Medicine, Oral Pathology, Oral Radiology, and Endodontology. 1997 Dec 1;84(6):668-71.

4. McGuire TP, Gomes PP, Freilich MM, Sándor GK. Congenital epulis: a surprise in the neonate. Journal of the Canadian Dental Association. 2006 Oct 1;72(8):747-50.

5. Kusukawa J, Kuhara S, Koga C, Inoue $T$. Congenital granular cell tumor (congenital epulis) in the fetus: a case report. Journal of oral and maxillofacial surgery. 1997 Nov 1;55(11):1356-9.

6. Hasanov A, Musayev J, Onal B, Rahimov C, Farzaliyev I. Gingival granular cell tumor of the newborn: a case report and review of literature. Turk Patoloji Derg. 2011;27(2):161e3.

7. Gupta O, Arora R, Gupta K, Sharma U. Congenital granular cell lesion in newborn mandible. Niger J Clin Pract. 2013;16(3):401e3.

8. Inan $\mathrm{M}$, Yalcin $\mathrm{O}$, Pul M. Congenital fibrous epulis in the infant. Yonsei Med J. 2002;43:675-7.

9. Messina M, Severi FM, Buonocore G, Molinaro F, Amato G, Petraglia F. Prenatal diagnosis and 
multidisciplinary approach to the congenital gingival granular cell tumor. Journal of pediatric surgery. 2006 Oct 1;41(10):e35-8.

10. Vered M, Dobriyan A, Buchner A. Congenital granular cell epulis presents an immunohistochemical profile that distinguishes it from the granular cell tumor of the adult. Virchows Arch. 2009;454(3):303e10.

11. Charrier JB, Droullé P, Chassagne JF, Vignaud JM, Stricker M. Obstructive congenital gingival granular cell tumor. Annals of Otology, Rhinology \& Laryngology. 2003 Apr;112(4):388-91.
12. Masson P, Sathi AE, Tizeggaghine A, Touati K, Gabriel BM. Tumeur à cellules granuleuses de la gencive chez le nouveau-né. Archives de pédiatrie (Paris). 2001;8(5):556-7.

13. Bilen BT, Alaybeyoğlu N, Arslan A, Türkmen E, Aslan S, Çelik M. Obstructive congenital gingival granular cell tumour. International journal of pediatric otorhinolaryngology. 2004 Dec 1;68(12):1567-71.

14. Saki N, Araghi S. Multiple congenital epulis in alveolar ridges of maxilla and mandible in a newborn: a rare case report. Case Rep Otolaryngol. 2014;2014:606985. 